\title{
EFFECT OF SOME ANTIBIOTIC COMPOUNDS IN GOSSYPIUM ON THE POST-EMBRYONIC DEVELOPMENT OF SPOTTED BOLLWORM (EARIAS VITTELLA)
}

\author{
H. C. SHARMA* and R. A. AGARWAL \\ Indian Agricultural Research Institute, New Delhi 110 012, India
}

\begin{abstract}
The antibiotic activity of some compounds, and of plant extracts, was bioassayed by incorporating them in a wheat germ diet developed for rearing cotton spotted bollworm (Earias vittella $F$.). Acetone extract of square powder caused maximum mortality followed by gossypol, tannic acid, other tannins and anthocyanins. Hexane extract of bolls did not affect larval survival. Rutin, anthocyanins and ether fractions of the ethanol extract decreased \% pupation of larvae while in diets containing gossypol and tannic acid. none of the larvae could reach pupal stage.

Some of the larvae were unable to spin the silken cocoons when reared on diets containing gossypol, tannins, anthocyanins and rutin. Tannins and anthocyanins increased the developmental period of insects. All the compounds or solvent extracts except hexane extract of bolls decreased pupal weight. It is suggested that gossypol, tannins, anthocyanins and other secondary substances present in cotton squares and bolls could be utilized as a source of biochemical resistance against $E$. vittella.
\end{abstract}

The spotted bollworm, Earias vittella is a serious pest of cotton in India (Sohi, 1964), China and Southeast Asia (Chang et al., 1963), and causes serious crop losses every year. Host plant resistance can be used as one of the methods to combat this pest. One of the mechanisms contributing to resistance could be the presence of chemicals with antibiotic activity against insects. This was investigated by incorporating plant extracts or pure compounds into artificial diet.

Gossypol had been found to affect the survival and larval weight of Earias insulana, Pectinophora gossypiella and Heliothis spp. (Meisner et al., 1977; Shaver \& Parrot, 1970; Bottger \& Patana, 1966 and Shaver \& Garcia, 1973). Other pigments including quercitin, quercitrin, rutin, morin and quercimetrin had been found toxic to Heliothis virescens and $P$. gossypiella (Lukefahr \& Martin, 1966, Shaver \& Lukefahr, 1969). Acetone extract and P . hemigossypolone had been found to inhibit growth of $H$. virescens (Shaver \& Lukefahr, 1971, Gray et al., 1976). These growth inhibitors were later referred to as heliocides (Stipanovic et al., 1976; 1977) which supplement the toxicity of gossypol but themselves are of mi-

\footnotetext{
* Sorghum Entomologist. International Crops Research Institute for the Semi-Arid Tropics, ICRISAT Patancheru P.O.. 502 324. A.P.. India
}

nor importance as resistance factors (Elliger et al., 1978).

\section{MATERIALS AND METHODS}

The diet developed by Pant \& Anand (1972) showed a very slow rate of development of $E$. vittella. However, the diet prepared after modifying the diet developed for pink bollworm (Raulston, 1971) showed normal development and higher rate of survival of spotted bollworm larvae.

The composition of vitamin mixture which was different from pink bollworm diet consisted of niacinamide ( $1 \mathrm{mg}$ ), calcium pantothenate $(1 \mathrm{mg})$, thiamine hydrochloride $(.25 \mathrm{mg})$, riboflavin $(.5 \mathrm{mg})$, pyridoxine hydrochloride $(.25 \mathrm{mg})$, folic acid $(.25 \mathrm{mg})$, biotin $(.02 \mathrm{mg})$, $\mathrm{B} 12(.002 \mathrm{mg})$ and inositol $(.2 \mathrm{mg}) / 100 \mathrm{ml}$ of diet.

The modified diet was prepared as follows. Agar was heated in $90 \mathrm{ml}$ of distilled water till it became transparent. The solid ingredients were put into a homogenizer along with the hot agar and blended for 5 min. The ingredients $\mathrm{KOH}, \mathrm{CH}_{3} \cdot \mathrm{COOH}, \mathrm{HCHO}$, and vitamin mixture were then added and blending continued for another $10 \mathrm{~min}$. Aliquots $(15 \mathrm{ml})$ of the hot mixture were poured into glass vials $(25 \mathrm{ml} \mathrm{ca-}$ pacity). Vials were plugged with non-absorbent cotton and kept in a refrigerator for $2 \mathrm{hr}$ for solidification. A groove was made in the 
diet on one side of the vial by drawing a sterilized glass rod along the glass wall. The diet was kept at rearing temperature of $30^{\circ}$ for $6 \mathrm{hr}$ before introducing the newly hatched larvae into it. The larvae were kept individually.

Rutin and tannic acid were obtained commercially, while gossypol was extracted from the pigment glands of seeds (Sharma, 1979). The method given by Chan \& Waiss Jr (1978) was followed for extracting tannins and that of Neelkantan \& Seshadri (1936) for extracting anthocyanins.

The alcoholic extract of bolls was fractionated between diethylether and water. The two fractions were dried in a water bath. Ether-soluble components were dark brown and water-soluble components dull red. The acetone extract of bolls of variety Sanguineum (Gossypium arboreum) was also taken (1 g bolls $/ 1 \mathrm{ml}$ of acetone).

Gossypol, tannic acid, rutin, condensed tannins (methanolic extract), tannins in water fraction of ethanol, hexane fraction and ethersoluble fraction of ethanolic extract were tested at $0.1 \%$ concentration in artificial diet (100 mg per $100 \mathrm{~g}$ of diet). Acetone extract was tested at $1 \mathrm{ml} / 100 \mathrm{ml}$ of diet. Controls with acetone were not kept. In hot diets, most of the acetone got evaporated. Rearing was carried out at $30^{\circ}$ in a B.O.D. incubator. Observations were recorded on larval survival, pupation, adult emergence, pupal weight, and lar- val and pupal developmental periods. All the tests were carried out simultaneously.

\section{RESULTS AND DISCUSSION}

The wheat germ diet developed for $E$. vittella was quite good as shown in control (Table I). The effect of different antibiotic compounds on the larval survival, pupation and adult emergence is given in Table $I$. Ether fraction of ethanol extract at $0.1 \%$ concentration caused $34.6 \%$ larval mortality which increased to $57 \%$ at $0.25 \%$ concentration. Diet containing acetone extract of square powder was found to be most unsuitable followed by gossypol and tannic acid. Tannins and anthocyanins also showed adverse effect on establishment of first-instar larvae. However, hexane extract did not reduce larval survival. On diets containing acetone extract of square powder, gossypol, and tannic acid, none of the larvae could pupate. On adult emergence, rutin showed a more pronounced effect followed by anthocyanins, tannins, acetone extract, water and ether fractions of ethanol extract. In diets containing gossypol, tannins, anthocyanins and rutin, some of the larvae either could not pupate or were unable to spin the silken cocoons. No adults emerged from such pupae.

Ether fraction and hexane extract did not affect larval and pupal developmental period. Tannins and anthocyanins increased the larval period by 7 and 9 days, respectively. However,

TABLEI

Effect of some antibiotic compounds on the post-embryonic development of spotted bollworm, Earias vittella $F$.

No. Compound/extract

$$
\begin{array}{cc}
\text { Conc. No. } & \text { Larval } \\
(\%) \text { insects } & \begin{array}{c}
\text { sur- } \\
\text { vival }
\end{array}
\end{array}
$$

1 Ethanol extract a) Ether fraction

b) Water fraction

2 Tannins (methanol extract)

3 Anthocyanins (Ethanol extract of flowers)

Hexane extract (bolls) Acetone extract (squares) Acetone extract (bolls) Gossypol

Tannic acid

Rutin

Artificial diet (control)

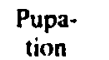

tion

Emer- Naked

gence pupae lopmental weight growth pcriod *** (mg) index

$22 \pm 0.3 \quad 56 \pm 3 \quad 9.0$

$\begin{array}{lll}22 \pm 0.3 & 56 \pm 3 & 9.0 \\ 20 \pm 0.2 & 40 \pm 4 & 7.5\end{array}$

$25 \pm 0.547 \pm 1 \quad 4.9$

$31 \pm 1.044 \pm 3 \quad 5.0$

$29 \pm 1.0 \quad 37 \pm 3 \quad 4.4$

$100.0 \quad 58.0$

$76.5 \quad 51.9$

$100.0 \quad 100.0 \quad 0 \quad 21 \pm 0.262 \pm 2 \quad 7.9$

0

$\overrightarrow{0}$

0

20. 0

100)
*Adult growth
index

4.0
0.5
3.1
1.9
1.8
4.8
-
2.7
-
-
4.5

- Larval growth index $=\%$ pupation/larval period

** Adult growth index $=\%$ adult emergence/total developmental period

*** Time between hatching of eggs and emergence of adults 
there was no effect on pupal development which was completed in $9-12$ days compared to 9.8 days on artificial diet. These compounds increased the total period required for com. pleting post-embryonic development by $9-10$ days.

Ether fraction and water fractions of alco. holic extract, tannins, anthocyanins and acetone extract reduced pupal weight. Anthocyanins reduced the pupal weight to the minimum, followed by acetone extract, tannins and water fraction of ethanol extract.

The overall antibiotic effects of different compounds can be seen from the ratio between $\%$ pupation and adult emergence and the time taken for completing larval and total development. Tannins, anthocyanins and water and ether fractions of ethanol extract of bolls considerably affected the growth indices based on larval period and \% pupation.

Hexane extract increased the growth index (based on total developmental period and \% adult emergence) over artificial diet. Ether and water fractions of ethanol extract, tannins, anthocyanins and acetone extract reduced the growth index considerably over artificial diet by 0.57 to 4.09 units.

Gossypol and tannin content of cotton lines had been found to increase larval and total developmental period (Sharma, 1979). This activity was also confirmed when these compounds were incorporated into artificial diet. Gossypol from bolls affected $\%$ pupation, while tannins affected \%o adult emergence.

Gossypol $(0.1 \%)$ appeared to be more toxic to $E$. vittella as compared to $E$. insulana (Meisner et al., 1977). Gossypol has earlier been found to affect the development of $P$. gossypiella (Shaver \& Parrot, 1970) and Heliothis spp. (Shaver et al., 1970). Rutin reported to be less toxic against $H$. virescens (Lukefahr \& Martin, 1966) was found to be highly toxic to $E$. vittella. Antibiotic activity of a condensed tannin had been reported against $H$. virescens (Chan \& Waiss, 1978). Tannins extracted from square buds were found to exercise considerable antibiotic effect against $E$. vittella.

\section{ZUSAMMENFASSLNG}

Wirkung einiger antibiotischer Verbindungen in Gossypium auf die nachembryonale Entwicklung von Earias vittella

Die antibiotische Wirkung einiger Verbindungen und Pflanzenextrakte wurde getested, indem sie in einen Weizenkeimnährboden für Raupen von Earias vittella $\mathrm{F}$. gemischt wurden. Die grösste Mortalität wurde mit Azetonextrakt von Blütenknospenpulver erzielt, gefolgt von Gossypol, Gerbsäure. Gerbstoffen und Anthocyaninen. Hexanextrakt von Kapseln beeinflusste das Überleben der Raupen nicht. Rutin. Anthocyanine und andere Fraktionen des Äthanolextrakts verminderten den Verpuppungsprozentsatz der Raupen. In Nährböden, welche Gossypol und Gerbsäure enthielten, erreichte keine Raupe das Puppenstadium.

Einige Raupen von den Nährböden mit Gossypol, Gerbstoffen, Anthocyaninen und Ruttin waren nicht in der Lage Seidencocons zu spinnen. Gerbstoffe und Anthocyanine verlängerten die Entwicklungsdauer der Insekten. Alle Verbindungen und Lösungsmittelextrakte, ausser dem Hexanextrakt von Kapseln, reduzierten das Puppengewicht. Es wird vermutet, dass Gossypol, Gerbstoffe. Anthocyanine und andere Sekundärsubstanzen in Baumwollknospen und -kapseln als Quelle biochemischer Resistenz gegen $E$. vittella verwendet werden könnten.

\section{REFERENCES}

Bottger, G. T. \& Patana, K. (1966). Growth, development and survival of certain Lepidoptera fed gossypol in diet. J. econ. Entomol. 59: 11661168.

Chan. B. G. \& Waiss Jr.. A. C. (1978). Condensed tannin, an antibiotic chemical from Gossypium hirsutum. J. Insect Physiol. $24: 113-118$.

Chang. G. S., Meng. H. L. \& Bao, J. A. (1963). The status of the spotted bollworms, Earias fabia (Stoll.) and $E$. insulana (Boisd.) after the changes of cultural system in Lukang Poashan district, Yunnan Province. Acta. ent. Sinica. 12 : 28.

Elliger, C. A., Chan, B. G. \& Waiss Jr., A. C. (1978). Relative toxicity of minor cotton terpenoids compared to gossypol. J. econ. Entomol. $71: 161-164$

Gray, J. R., Marby. T. J., Bell, A. A. \& Stipanovic, R. D. (1976). P-hemi-gossypolone. A sesquiterpenoid aldehyde quinone from Gossypium hirsutum. J. Chem. Soc. Commun. 109-110.

Lukefahr, M. J. \& Martin, D. F. (1966). Cotton plant pigments as a source of resistance to the bollworm and tobacco budworm. J. econ. Entomol. $59: 176-179$.

Meisner, J.. Kehat. M.. Zur, M. \& Ascher, K. R. S. (1977). The effect of gossypol on the larvae of spiny bollworm. Earias insulana. Ent. exp. \& appl. $22: 301-303$.

Neelkantan, K. \& Seshadri, T. R. (1936). Pigments of cotton flowers. Part IV. Proc. Ind. Acad. Sci. (A) $5: 537-564$.

Pant, J. C. \& Anand, M. (1972). An artificial diet for spotted bollworm, Earias fabia Stoll. Entomologists' Newsletter $2: 45-46$. 
Raulston, J. R. (1971). A practical diet containing cotton seed for rearing pink bollworm. J. econ. Entomol. 64 : 1021-1023.

Sharma, H. C. (1979). Influence of chemical components in Gossypium on the behaviour and biology of spotted bollworm (Earias spp.) Ph.D. Thesis. Indian Agricultural Research Institute, New Delhi, $247 \mathrm{pp}$.

Shaver, T. N. \& Garcia, J. A. (1973). Gossypol content of cotton flower buds. J. econ. Entomol. 6 : $327-329$.

Shaver, T. N. \& Lukefahr, M. J. (1969), Effect of flavonoid pigments and gossypol on the growth and development of bollworm, tobacco budworm and pink bollworm. J. econ. Entomol. 62 : 643646.

Shaver. T. N. \& Lukefahr, M. J. (1971). A bioassay technique for detecting resistance of cotton strains to tobacco budworms. J. econ. Entomol. $64: 1274-1277$.

Shaver, T. N. \& Parrot, W. L. (1970). Relationship of larval age to toxicity of gossypol to bollworm, tobacco budworm and pink bollworms. J. econ. Entomol. 63 : 1802-1804.

Shaver, T. N., Lukefahr. M. J. \& Garcia. J. A (1970). Food utilization. ingestion and growth of larvae of bollworm and tobacco budworms on diets containing gossypol. J. econ. Entomol. 63 : $1544-1546$.

Sohi, G. S. (1964). Pests of cotton. In: Entomology in India. Ed.: N. C. Pant, Entomological Society of India. pp. 111-148.

Stipanovic, R. D. Bell, A. A. \& Lukefahr, M. J. (1976). Natural insecticides of cotton, structural analysis and toxicology of Heliocides. 172nd Nat. Mfg. Amer. Chem. Soc. Aug. 29-Sept. 3, 1976. San Francisco, Pest Div. Abs. No. 78.

Stipanovic, R. D., Bell, A. A., O'Brien. D. H. \& Lukefahr, M. J. (1977). Heliocide-H2. An insecticidal sesquiterpenoid from cotton (Gossypium). Tebrahednon Lett. 567-570. 